\title{
Hepatobiliary Scintigraphy in 2014
}

\author{
Harvey A. Ziessman \\ Division of Nuclear Medicine, Russell H. Morgan Department of Radiology and Radiological Science, Johns Hopkins Medical \\ Institute, Baltimore, Maryland
}

CE Credit: For CE credit, you can access the test for this article, as well as additional JNMT CE tests, online at https://www.snmmilearningcenter.org. Complete the test online no later than December 2017. Your online test will be scored immediately. You may make 3 attempts to pass the test and must answer $80 \%$ of the questions correctly to receive $1.0 \mathrm{CEH}$ (Continuing Education Hour) credit. SNMMI members will have their CEH credit added to their VOICE transcript automatically; nonmembers will be able to print out a CE certificate upon successfully completing the test. The online test is free to SNMMI members; nonmembers must pay $\$ 15.00$ by credit card when logging onto the website to take the test. Participants who have already taken the exam using JNM and passed cannot retake the exam.

Cholescintigraphy with $99 \mathrm{~m}$ Tc-hepatobiliary radiopharmaceuticals has been an important, clinically useful diagnostic imaging study for almost 4 decades. It continues to be in much clinical demand; however, the indications, methodology, and interpretative criteria have evolved over the years. This review will emphasize state-of-the-art methodology and diagnostic criteria for various clinical indications, including acute cholecystitis, chronic acalculous gallbladder disease, high-grade and partial biliary obstruction, and the postcholecystectomy pain syndrome, including sphincter-of-Oddi dysfunction and biliary atresia. The review will also emphasize the use of diagnostic pharmacologic interventions, particularly sincalide.

Key Words: hepatobiliary scintigraphy; cholescintigraphy; acute cholecystitis; chronic cholecystitis; chronic acalculous gallbladder disease; biliary dyskinesia

J Nucl Med Technol 2014; 42:249-259

DOI: 10.2967/jnumed.113.131490

$\mathbf{N}$ ow almost 4 decades old, ${ }^{99} \mathrm{~m} \mathrm{Tc}$ cholescintigraphy continues to be a radionuclide imaging study in much clinical demand. Its strength lies in the fact that the diagnostic information provided defines pathophysiology rather than anatomy.

${ }^{123} \mathrm{I}$ - and ${ }^{123}$ I-rose bengal were the first clinically useful cholescintigraphic agents; however, image quality was relatively poor (Fig. 1). ${ }^{99 \mathrm{~m}}$ Tc-hepatobiliary radiopharmaceuticals began to be widely used by the early 1980s.

The discovery of ${ }^{99 \mathrm{~m}}$ Tc-hepatobiliary (HIDA) radiopharmaceuticals was by chance. During investigation for a cardiac imaging radiopharmaceutical, it was found that $99 \mathrm{~m} \mathrm{Tc}-$ labeled lidocaine was not a good cardiac imaging agent but

\footnotetext{
Received Dec. 3, 2013; revision accepted Mar. 3, 2014.

For correspondence or reprints contact: Harvey A. Ziessman, Johns Hopkins Medical Institute, John Hopkins Outpatient Center, 601 N. Caroline St., Suite 3231, Baltimore, MD 21278.

E-mail: hziessm1@jhmi.edu

Published online Apr. 17, 2014.

COPYRIGHT (C 2014 by the Society of Nuclear Medicine and Molecular Imaging, Inc.
}

cleared through the hepatobiliary system. With chemical modification, ${ }^{99 \mathrm{~m}} \mathrm{Tc}-\mathrm{HIDA}$ imaging agents were born. Loberg et al. reported on this in $1976(1)$. Its structure is simply that of 2 lidocaine analogs bichelated to ${ }^{99 \mathrm{~m}} \mathrm{Tc}$ by iminodiacetic acid (IDA) (Fig. 2). HIDA (hepatoiminodiacetic acid) has long been used as a generic term for cholescintigraphy.

Modifications of the benzene ring of the lidocaine analogs resulted in an alphabet soup of hepatobiliary radiopharmaceuticals (PIPIDA, BIDA, EIDA, DIDA, DISIDA, etc.), each with different rates of hepatic uptake and clearance. The first 99mTc-HIDA radiopharmaceutical was approved for clinical use by the Food and Drug Administration in 1982. Dimethyl IDA (lidofenin [Technescan; Mallinckrodt]) was a major advance, but image quality and diagnostic utility were suboptimal in patients with serum bilirubin levels above $5.0 \mathrm{mg} / \mathrm{dL}$. It is no longer available.

In 1986, the Food and Drug Administration approved 99mTc-disofenin (diisopropyl-IDA [Hepatolite; Pharmalucence]). It provided images of diagnostic quality with bilirubin levels of as high as 25-30 mg/dL. In 1993, 99mTc-mebrofenin (bromotriethyl-IDA [Choletec; Bracco]) was approved. It had higher liver extraction (98\% vs. $89 \%$ ) and more rapid biliary clearance than ${ }^{99 \mathrm{~m}} \mathrm{Tc}$-disofenin (half-life of $19 \mathrm{~min}$ vs. $17 \mathrm{~min}$ ).

After intravenous injection, ${ }^{99 \mathrm{~m}}$ Tc-HIDA radiopharmaceuticals are transported in the blood bound to serum albumin. They dissociate from albumin in the hepatic perisinusoidal space and are extracted by hepatocytes by receptor-mediated endocytosis, similar to bile salts, free fatty acids, and bilirubin. They then follow the same metabolic pathway as bilirubin, except that they are secreted into biliary caliculi unchanged, without undergoing conjugation.

This review will emphasize modern-day use and newer developments that affect clinical practice. Space does not permit review of all of the many clinical indications for cholescintigraphy (i.e., acute cholecystitis, chronic cholecystitis, acute biliary obstruction, partial biliary obstruction, sphincter-of-Oddi dysfunction, biliary atresia, biliary leak, biliary stent patency, enterogastric bile reflux, complications 


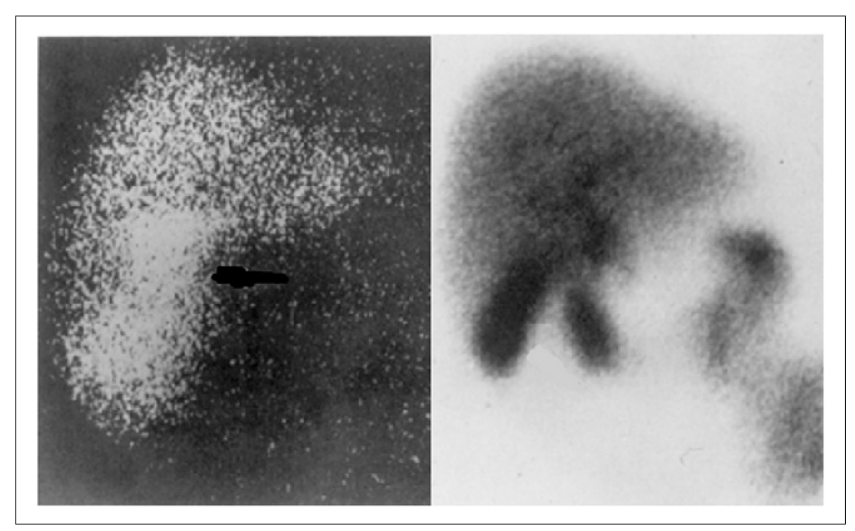

FIGURE 1. ${ }^{123}$ I-rose bengal cholescintiscan (left) and ${ }^{99 m}$ TcHIDA cholescintiscan (right).

from the biliary diversion procedure, complications after liver transplantation, differential diagnosis of hepatic tumors, and prediction of remnant liver function after partial hepatectomy).

\section{ACUTE CHOLECYSITIS}

Acute cholecystitis is the most common clinical indication for cholescintigraphy. Patients present with acute colicky pain in the right upper quadrant lasting hours or days. Except for low-grade fever and a moderately elevated leukocyte count, laboratory findings (including liver function studies) are usually normal. A few patients will have an elevated level of serum bilirubin caused by stones lodged in both the cystic and the biliary ducts or, less commonly, by an impacted cystic-duct stone compressing the adjacent hepatic or common bile duct (Mirizzi syndrome).

A sequence of pathophysiologic events occurs with acute cholecystitis. Initially the cystic duct is obstructed, usually by a stone. The gallbladder mucosa becomes edematous, followed by neutrophilic infiltration, then mucosal ulceration, hemorrhage, and necrosis, and ultimately, if left untreated, the complications of perforation, gangrene, and abscess (2).

\section{Ultrasonography}

Ultrasonography is often part of the initial work-up for suspected hepatobiliary disease. It is readily available, does not use ionizing radiation, and can detect various intraabdominal diseases in addition to acute cholecystitis, such as biliary obstruction, pancreatitis, and tumors.

The sonographic findings of acute cholecystitis are usually nonspecific and secondary pathologic findings. Gallstones are present in most patients with acute cholecystitis; however, because cholelithiasis is common in the general population and often remains asymptomatic for a lifetime, its presence is not diagnostic, except that the lack of gallstones makes a nonbiliary process more likely.

The sonographic findings of gallbladder wall thickening, dilatation, pericholecystic fluid, and sludge are nonspecific. Intramural sonolucency, due to edema, and the sonographic Murphy sign are more specific, but the former does not have high sensitivity and the latter is observer-dependent and can be unreliable. The more of these findings that are present, the greater the likelihood will be that the diagnosis is acute cholecystitis (3). However, the ultrasonographic criteria used to diagnose acute cholecystitis vary.

\section{Accuracy of Cholescintigraphy and Ultrasonography}

A problem with reading the published literature about the relative accuracy of ultrasonography and cholescintigraphy to diagnose acute cholecystitis is the different histopathologic criteria that have been used (4). Strict criteria for acute cholecystitis require leukocyte infiltration and hemorrhagic necrosis. More liberal criteria would include edema. This inconsistency is most problematic when only a single diagnostic imaging technique is investigated. The accuracy of a test is most reliable when there is a direct comparison of two or more imaging methods using the same histopathologic criteria in the same patient population.

Although several published investigations have reported high accuracy for ultrasonography to confirm the diagnosis of acute cholecystitis, only a few have directly compared the relative accuracy of sonography and cholescintigraphy in the same investigation. Six of 7 direct-comparison published investigations have shown superior accuracy for cholescintigraphy over sonography (Table 1) (5-11). CT and MR are most useful for detection of suspected complications.

Cholescintigraphy demonstrates the primary underlying pathophysiology of acute cholecystitis, that is, obstruction of the cystic duct, and thus the ${ }^{99 \mathrm{~m}}$ Tc-HIDA radiopharmaceutical cannot enter the gallbladder. Stones are the cause of obstruction in more than $90 \%$ of patients, but stones are rarely visualized by anatomic imaging because of their small size and the sonographic acoustic problems in the small cystic duct.

\section{Patient Preparation}

Patients should ingest nothing by mouth for 3-4 h before injection of the ${ }^{99 \mathrm{~m}} \mathrm{Tc}-\mathrm{HIDA}$ radiopharmaceutical. This interval allows time for the ingested meal to have passed though the proximal small bowel, where fat stimulates endogenous

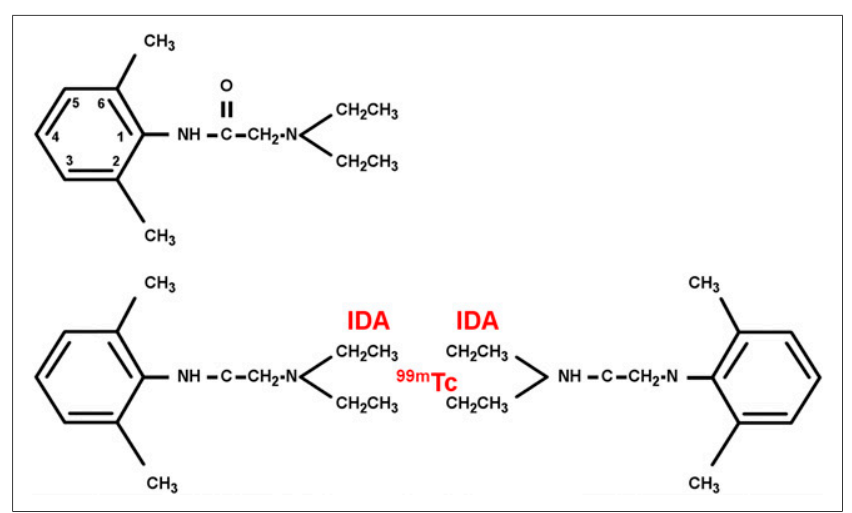

FIGURE 2. Chemistry of ${ }^{99 m} \mathrm{mc}-\mathrm{HIDA}$ radiopharmaceuticals: lidocaine (A) and $99 \mathrm{mTc}-$ mebrofenin (B). Two lidocaine analogs are bichelated to ${ }^{99 \mathrm{mT}} \mathrm{Tc}$ by IDA. 
TABLE 1

Accuracy of Ultrasonography vs. Cholescintigraphy for Acute Cholecystitis: Direct-Comparison Investigation

\begin{tabular}{|c|c|c|c|c|c|c|}
\hline \multirow[b]{2}{*}{ Publication } & \multirow[b]{2}{*}{ Year } & \multirow[b]{2}{*}{ No. of patients } & \multicolumn{2}{|c|}{ Cholescintigraphy } & \multicolumn{2}{|c|}{ Ultrasonography } \\
\hline & & & Sensitivity & Specificity & Sensitivity & Specificity \\
\hline Stadalnik et al. (5) & 1978 & 120 & 87 & 100 & 70 & 93 \\
\hline Zeman et al. (11) & 1981 & 200 & 98 & 81 & 67 & 82 \\
\hline Worthen et al. (8) & 1981 & 113 & 95 & 100 & 76 & 100 \\
\hline Ralls et al. (10) & 1982 & 59 & 86 & 84 & 86 & 90 \\
\hline Freitas et al. (6) & 1982 & 195 & 98 & 90 & 81 & 60 \\
\hline Samuels et al. (7) & 1983 & 194 & 97 & 93 & 97 & 64 \\
\hline Chatziioannou et al. (9) & 2000 & 107 & 92 & 89 & 40 & 89 \\
\hline
\end{tabular}

cholecystokinin release and thus gallbladder contraction, and then time for the gallbladder to relax. When patients are interviewed about when they last ate, a question on what they ate is helpful. A meal with at least $10 \mathrm{~g}$ of fat is required to contract and empty the gallbladder.

Patients who have been fasting for more than $24 \mathrm{~h}$ have had no stimulation to contract the gallbladder and will likely have concentrated viscous jellylike bile that can prevent entry of radiotracer and result in a false-positive study for acute cholecystitis. In these patients, sincalide (Kinevac; Bracco) should be administered before the study to empty the gallbladder. The pharmacologic dose $(0.02 \mu \mathrm{g} / \mathrm{kg})$ should be infused over $60 \mathrm{~min}$, similar to what is described later in this review for optimal gallbladder contraction. However, some patients with chronic cholecystitis may have poorly contracting gallbladders and thus not respond to the sincalide, resulting in a false-positive study. The ${ }^{99} \mathrm{~m}$ Tc-HIDA agent should be injected at least $30 \mathrm{~min}$ later to provide sufficient time for gallbladder relaxation.

\section{Scintigraphic Protocol}

The imaging protocol for cholescintigraphy has become fairly standardized (12). A 60-s blood flow phase (1- to 3-s frames) is optional. The diagnostic yield is not high; however, increased flow to the region of the gallbladder fossa can be seen in severe cases of acute cholecystitis and in other causes of abdominal pain, such as intraabdominal infection or a vascular tumor. After the flow study, 1-min dynamic images are acquired for the remaining $59 \mathrm{~min}$.

In the setting of good hepatic function and biliary clearance, nonfilling of the gallbladder is diagnostic of acute cholecystitis but must persist on delayed images for up to $4 \mathrm{~h}(13)$ or for $30 \mathrm{~min}$ after morphine infusion (14).

Gallbladder filling after $1 \mathrm{~h}$ with normal biliary-to-bowel transit is usually due to chronic cholecystitis (15). The presence of intestinal transit before gallbladder filling during the first hour of imaging is also suggestive of chronic cholecystitis (16). Delayed gallbladder filling is caused by a functional resistance to flow through the cystic duct, often due to viscous concentrated bile within the gallbladder, gallstones, chronic mucosal thickening, and fibrosis. Visualization of the gallbladder by the end of the first hour after these patients are pretreated with cholecystokinin is consid- ered evidence for a functional mechanism (17). Other scintigraphic findings suggestive of chronic cholecystitis include delayed biliary-to-bowel transit with normal gallbladder filling (18).

The most common cause for a false-positive finding of acute cholecystis is chronic cholecystitis. Therefore, the prevalence of chronic cholecystitis in the population under study affects the overall specificity of the test. However, most patients with chronic cholecystitis have gallbladder filling by $1 \mathrm{~h}$.

The use of morphine sulfate (MS) is often preferred over the delayed imaging method for confirmation of the diagnosis of acute cholecystitis because a shorter time is required and the problem of rapid ${ }^{99 \mathrm{~m}} \mathrm{Tc}-\mathrm{mebrofenin}$ liver clearance is reduced (19). An additional 74-111 MBq (2-3 $\mathrm{mCi}$ ) of ${ }^{99 \mathrm{~m}} \mathrm{Tc}-\mathrm{mebrofenin}$ are often administered at the time of morphine infusion if there has been substantial liver clearance. This procedure, although it would probably be useful, has not been standard for the delayed imaging method. The MS method is at least as accurate as and perhaps more accurate than the delayed imaging method (20).

Subanalgesic doses of intravenous MS contract the sphincter of Oddi and increase intrabiliary pressure, causing preferential flow through the cystic duct if it is patent. A weight-based dose of MS is recommended, $0.04 \mathrm{mg} / \mathrm{kg}(20)$. Enterogastric reflux is not uncommon, probably because of relaxation of the pyloric sphincter. Levorphanol or meperidine (Demerol; Abbott Laboratories) could theoretically be used if MS is unavailable, but there are few published data to confirm its accuracy $(21)$.

MS is usually administered $60 \mathrm{~min}$ after ${ }^{99 \mathrm{~m}} \mathrm{Tc}-\mathrm{HIDA}$ injection. Earlier infusion, such as at $30 \mathrm{~min}$, has been successfully used, but one loses the ability to differentiate chronic from acute cholecystitis (22). MS should not be given unless there is good biliary duct clearance and biliary-to-bowel transit; otherwise, post-MS differentiation of a pathologic partial biliary obstruction from an MS pharmacologic effect may not be possible. There is no contraindication to MS administration, except for a past allergic reaction. MS is not useful in patients who do not have a functioning sphincter of Oddi (e.g., patients with a common duct stent or sphincterotomy). Like the delayed imaging method, there is likely to be preferential biliary 
duct drainage that could result in a false-positive finding of acute cholecystitis (23).

\section{False-Positive Findings of Acute Cholecystitis}

Although the sensitivity of $99 \mathrm{~m}$ Tc-HIDA radiopharmaceutical for the diagnosis of acute cholecystitis is high $(95 \%-98 \%)$ and the specificity quite good $(90 \%)$, rare false-negative and somewhat more common false-positive findings occur (15). Patients who do not follow nothingby-mouth instructions is one reason for a false-positive finding, and patients who have been fasting or receiving hyperalimentation for greater than $24 \mathrm{~h}$ is another. A severe concurrent illness is an important cause for falsepositive findings $(24,25)$, reducing the specificity of the test to about $70 \%$. Patients with poor hepatocellular function may have a false-positive finding because of altered tracer pharmacokinetics, that is, slower uptake and clearance. Thus, the time required for visualization of the gallbladder and biliary-to-bowel transit is prolonged, and the usual diagnostic time intervals do not apply. Delayed imaging is often required, up to $24 \mathrm{~h}$.

\section{Cystic Duct Sign}

The cystic duct sign must not be misinterpreted as gallbladder filling (26). It is caused by dilation of the cystic duct secondary to distal cystic duct obstruction. However, the radiotracer is seen somewhat medial to the gallbladder fossa as a focus that is smaller than expected for gallbladder filling. Misinterpretation as gallbladder filling can have serious patient-treatment consequences. SPECT/CT can help confirm the diagnosis (Fig. 3) (27).

During cholescintigraphy that has been ordered to confirm or exclude acute cholecystitis, acute or partial obstruction of the common bile duct may be seen instead. Symptoms of the two entities can be similar, and as many as $70 \%$ of these patients do not have biliary dilatation on ultrasonography (28).

\section{Rim Sign}

The rim sign, that is, increased uptake of the ${ }^{99 \mathrm{~m}} \mathrm{Tc}-$ HIDA agent in the liver adjacent to the gallbladder fossa, is a useful ancillary finding seen in about $25 \%-35 \%$ of patients with acute cholecystitis (29-31). This scintigraphic finding is seen in patients in the later stages of the histopathologic spectrum of the disease, that is, with gallbladder hemorrhage, necrosis, and ulceration (29), and has been associated with an increased incidence of gangrene and perforation (30). Although not sensitive for the diagnosis of acute cholecystitis, it is very specific. The rim sign is caused by severe gallbladder inflammation extending to adjacent liver, resulting in increased blood flow to that area, increased delivery of the radiotracer to that region of the liver, and thus increased uptake. In some patients, surgeons have described fibrinous inflammatory adhesions that can make it difficult to remove the gallbladder from the adjacent liver.

\section{Acalculous Form of Acute Cholecystitis}

Acalculous acute cholecystitis occurs in less than $10 \%$ of patients with acute cholecystitis. No stones are present in the gallbladder or cystic duct. This entity typically occurs in patients who have had multiple traumatic injuries, extensive serious burns, postoperative complications, shock, sepsis, or other serious illnesses. Acalculous acute cholecystitis is associated with a high morbidity and mortality, at least partly because the disease presents atypically and may be obscured by the primary illness.

Most patients with acute acalculous cholecystitis have cystic duct obstruction not caused by a stone. In some cases, the obstruction is due to kinking, fibrosis, adhesive bands, anomalous vessels, tumor, or lymphadenopathy. In most cases the cause is inspissated bile, cellular debris, and local edema. In most of these patients, the diagnosis can be made with cholescintigraphy. However, perhaps a quarter of patients with acute acalculous cholecystitis do not have cystic duct obstruction but rather direct inflammation of the gallbladder wall secondary to sepsis, toxemia, or ischemia. Because there is no cystic duct obstruction, the gallbladder may visualize on ${ }^{99 \mathrm{~m}} \mathrm{Tc}$ cholescintigraphy, resulting in a false-negative finding for acute cholecystitis. The diagnostic sensitivity of cholescintigraphy varies in the literature, and patient numbers are small; however, it is probably in the range of $70 \%-80 \%$, compared with more than $95 \%$ for acute calculous cholecystitis (27).

In patients with a clinically suspected false-negative finding of acute acalculous cholecystitis, the diagnosis can sometimes still be made. If present, the rim sign will confirm the diagnosis with a high degree of certainty. In others, sincalide can be helpful. Diseased gallbladders, acute or chronic, do not contract well. Normal gallbladder
FIGURE 3. Cystic duct sign. (A) ${ }^{99 \mathrm{mTC}-}$ HIDA scan ordered to rule out acute cholecystitis. Images show focal accumulation of activity medial to usual position of gallbladder, which remains mostly unchanged over time. (B) Ten-minute SPECT/CT image in same patient shows that focal activity is in cystic duct just distal to occluding cystic duct stone. (Reprinted with permission of (27).)

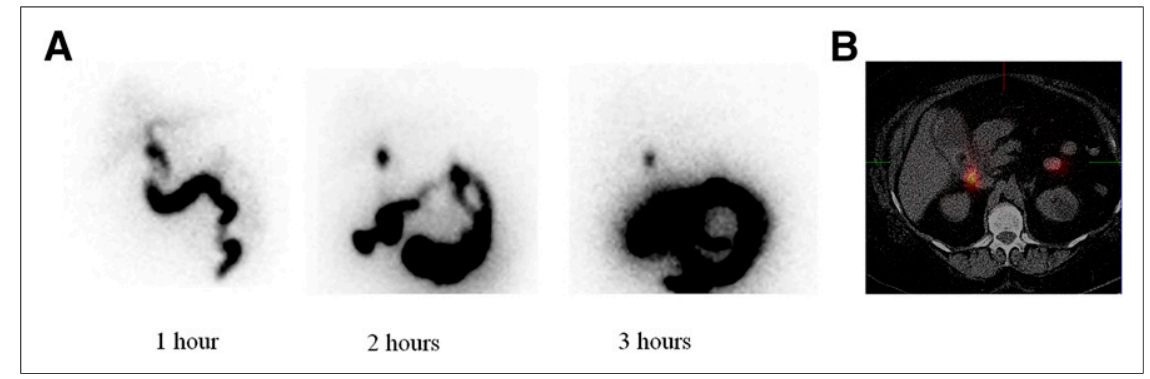


contraction rules out acute or chronic cholecystitis. However, poor gallbladder contraction will not allow differentiation between acute and chronic gallbladder disease.

Although patients with acute acalculous cholecystitis are sick and need surgical intervention, surgeons are often hesitant to operate on them without a firm diagnosis because of the high surgical risk. In these cases, radiolabeled leukocytes can be useful. ${ }^{111}$ In-labeled leukocytes have the advantage of having no hepatobiliary clearance (32). Images should be acquired early, at $4 \mathrm{~h}$, and if necessary at $24 \mathrm{~h}$. However, good results have been reported with 99m Tc-hexamethylpropyleneamine oxime leukocytes, despite clearance of the radiopharmaceutical through the hepatobiliary system (33). Imaging should be performed by $2 \mathrm{~h}$, before hepatobiliary clearance occurs.

\section{CHRONIC GALLBLADDER DISEASE}

Patients with chronic calculous cholecystitis present clinically with symptoms of recurrent biliary colic. Their physician often orders ultrasonography to confirm the diagnosis. Cholelithiasis is detected, and the patient is referred for cholecystectomy. These patients rarely have cholescintigraphy. On occasion, a referring physician suspects that the patient's abdominal pain may not be caused by the stones in the gallbladder and will request a radionuclide study of gallbladder ejection fraction (GBEF). Gallstones are common, but fewer than $15 \%$ of patients with gallstones followed for $20 \mathrm{y}$ developed biliary colic (34). A normal GBEF makes symptomatic chronic cholecystitis unlikely, confirming the clinician's suspicion that the patient has asymptomatic cholelithiasis and that another cause for the pain must be sought (35). There is no contraindication to sincalide infusion in patients with cholelithiasis.

Most patients referred for sincalide cholescintigraphy with GBEF are suspected to have chronic acalculous cholecystitis (CAGBD). Ultrasonography did not show stones. The acalculous form of the disease is reported to occur in approximately $5 \%-10 \%$ of patients with a final histopathologic diagnosis of chronic cholecystitis (34); however, recent laparoscopic studies suggest the frequency may be higher, perhaps $25 \%$ (36).

Many different names have been used for suspected cases of CAGBD, including cystic duct syndrome, gallbladder spasm, gallbladder dyskinesia, and functional gallbladder disease. These patients have recurrent biliary colic and poor gallbladder contraction, are cured by cholecystectomy, and usually have gallbladder histopathologic findings of lymphocyte infiltration and fibrosis similar to gallbladders with the calculous form of the disease but without stones. Patients with asymptomatic cholelithiasis do not have inflammatory changes of the gallbladder.

\section{Publications Confirming the Diagnostic Utility of GBEF}

Early studies published in the 1970s, using oral cholecystography and cholecystokinin or a fatty meal to stimulate gallbladder contraction, reported that the gallbladders of many patients with CAGBD contract poorly. However, published investigations reported conflicting results on whether this was a dependable diagnostic finding $(37,38)$. The methodology varied, interpretation was subjective, and cholecystokinin was often given as a bolus, a problem discussed below. When ${ }^{99 m}$ Tc-HIDA radiopharmaceuticals became available, many investigators were quick to realize that this question might be answered with quantitative cholecystokinin cholescintigraphy (39).

The first published investigation, reported by Topper et al. in 1980, found that GBEF was predictive of CAGBD and a good clinical response to cholecystectomy (40). By the early 1990s, at least 22 publications reported similar results. However, all but one were retrospective.

One of the largest retrospective studies was by FinkBennett, et al. published in 1991 in The Journal of Nuclear Medicine (41). They studied 374 patients referred for suspected CAGBD. Of 113 patients with a low GBEF who subsequently underwent cholecystectomy, 97\% had relief of their symptoms and $94 \%$ had histopathologic evidence of chronic cholecystitis. They infused sincalide, $0.02 \mu \mathrm{g} / \mathrm{kg}$, over $3 \mathrm{~min}$ and defined an abnormal GBEF as less than $35 \%$, for uncertain reasons. They had studied a group of asymptomatic healthy subjects, but only 9 had a GBEF greater than $35 \%$. The investigators certainly did not use these data to establish their reference values. However, as a result of this study with seemingly good results, many imaging clinics followed the authors' sincalide infusion protocol and reference values.

The methodology varied considerably among the retrospective investigations, which used different forms of cholecystokinin, different total doses administered (0.01$0.04 \mu \mathrm{g} / \mathrm{kg}$ ), different infusion lengths (bolus, 1-3 min, $15 \mathrm{~min}, 20 \mathrm{~min}$, and 30-45 $\mathrm{min}$ ), and different reference values (42). None of these studies established reference values based on the methodology they used. Curiously, 6 published retrospective investigations did not find that GBEF was predictive of CAGBD and good response to cholecystectomy (42).

The only prospective and randomized study was reported by Yap et al. It was published in the same month and year as the publication of Fink-Bennett et al. (41) but in the gastroenterology literature and thus was not familiar to most of the nuclear medicine community (43). This prospective study randomized - to surgical or nonsurgical therapy-patients referred with suspected CAGBD who had a low GBEF. They used a very different sincalide infusion method, $0.02 \mu \mathrm{g} / \mathrm{kg} / \mathrm{h}$ infused over $45 \mathrm{~min}$, with imaging and quantification at 60 min. Importantly, they established their own reference values based on 30 healthy subjects. An abnormal GBEF was found to be less than $40 \%$.

In this prospective randomized study, 92\% (10/11) of the patients with a low GBEF had resolution of their symptoms after cholecystectomy and had histopathologic evidence of chronic cholecystitis. Patients randomized to the nonsurgical 
arm continued to have pain, some severe enough to demand surgery, and they also had resolution of their symptoms after cholecystectomy. This is considered to be an excellent investigation, with the main limitation being that the number of subjects, 21, was not high.

\section{Reference Values for GBEF}

Cholecystokinin is a 33- to 58-amino-acid polypeptide hormone. The terminal octapeptide is the physiologically active form of the hormone. Sincalide is an analog of the terminal octapeptide. Kinevac is the only commercially available Food and Drug Administration-approved parenteral cholecystagogue. The only contraindication to sincalide is a history of a previous allergic reaction (quite rare) and pregnancy.

GBEF reference values after sincalide infusion vary with the dose administered and the infusion time. As early as 1985, there was evidence that methodology mattered. One study of 31 healthy subjects who received 1- to 2-min infusions of $0.015 \mu \mathrm{g} / \mathrm{kg}$ found that GBEFs varied between $7 \%$ and $85 \%(44)$. In another study, Sarva et al. studied 2 different groups of subjects, one with a 1-min infusion of sincalide, $0.02 \mu \mathrm{g} / \mathrm{kg}$, and another with a $45-\mathrm{min}$ infusion (45). The results showed higher GBEFs (mean, $77 \%$ vs. $52 \%$ ) and a considerably narrower range of response (65\%-96\% vs. $12 \%-92 \%)$ with the 45 -min infusion than with the 1-min infusion. These were not truly healthy subjects but rather symptomatic patients who were referred for cholescintigraphy but turned out to have nonbiliary causes for their pain. Both studies suggested considerable GBEF variability with short infusions in healthy subjects.

Two subsequent investigations studied proven healthy subjects with 2 different sincalide infusion methods on different days. Those who had a 3-min infusion of 0.01 or $0.02 \mu \mathrm{g} / \mathrm{kg}$ had extreme variability in GBEF (0\%-100\%), and clinically useful reference values could be established $(46,47)$. False-positive results, that is, a low GBEF with a 3-min infusion but a normal GBEF with a 30- or 60-min infusion in the same subjects, occurred in a third of subjects. Sincalide infusions of $30 \mathrm{~min}$ and $60 \mathrm{~min}$ in the same subjects showed much less variability, and reference GBEF values could be determined $(>30 \%$ and $>40 \%$, respectively).

In the same studies, it was shown that a 3-min infusion of sincalide $(0.37$ or $0.74 \mathrm{kBq}[0.01$ or $0.02 \mu \mathrm{Ci}] / \mathrm{kg})$ caused abdominal cramping or nausea in $50 \%$ of healthy subjects $(46,47)$. Those same subjects did not have pain with 30 - or 60-min sincalide infusions. Even 15-min infusions may cause abdominal symptoms in some subjects (48).

In the 1960s and 1970s, it was reported that a bolus infusion of cholecystokinin can result in spasm of the cystic duct and gallbladder neck, resulting in ineffective gallbladder contraction $(49,50)$. The described data suggest that the reason for the variable and often poor response to short infusions of sincalide may be caused by gallbladder sensitivity to the rapid nonphysiologic infusion of sincalide, causing a spasm of the cystic duct and gallbladder neck similar to that seen with bolus infusions (51).

It has been said often and wrongly that pain during sincalide infusion is diagnostic of chronic cholecystitis, because it reproduces the patient's pain. Although investigations have shown that this is not true, the erroneous idea persists (52). Pain seen with sincalide is dependent on dose rate and is unrelated to the presence of underlying disease. Slower infusions are a more physiologic infusion method, mimicking endogenous secretion of cholecystokinin in response to eating a fatty meal, and almost never result in nausea or abdominal discomfort (51).

A multicenter investigation was designed to determine the optimal methodology for sincalide infusion. The study was sponsored by the commercial distributor of Kinevac, Bracco Diagnostics, Inc., which provided an unrestricted grant to the Gastrointestinal Council of the Society of Nuclear Medicine (now morphed to the General Clinical Nuclear Medicine Council of the Society of Nuclear Medicine and Molecular Imaging). Bracco had no input into the study design, analysis of results, or conclusions. The study directly compared 15-, 30-, and 60-min sincalide infusions $(0.02 \mu \mathrm{g} / \mathrm{kg})$ in 60 healthy subjects, 15 each at 4 different institutions (48). The 3 different sincalide infusion studies were performed at 2-3 d apart. The purpose of the investigation was to determine which methodology showed the least variability in subject response and to establish reference values. The investigation found that the 60-min infusion method had the least variability (percentage coefficient of variance) and the narrowest range for GBEF reference values (Fig. 4). The lower range of normal was $38 \%$, similar to the prospective study of Yap et al. $(<40 \%)$ using a similar but not identical protocol (43).

An expert panel of gastroenterologists, surgeons, and nuclear medicine physicians subsequently met and published a consensus report in both the gastroenterology literature and the nuclear medicine literature $(53,54)$. The panel recommended that the 60 -min method for infusing sincalide described in the multicenter trial should become the standard, specifically, $0.02 \mu \mathrm{g} / \mathrm{kg}$ infused at a constant rate via an infusion pump or slow drip over $60 \mathrm{~min}$, with imaging and quantification over the entire 60-min period. Some gastroenterologists think there are insufficient evidence-based data on the utility of the GBEF study (55). The panel therefore also recommended that a large prospective and randomized multicenter trial be initiated to confirm that a radionuclide GBEF study can diagnose CAGBD and predict a good response to cholecystectomy, using the panel's recommended infusion method (56).

Reference values are not necessarily the same thing as determination of a GBEF cutoff value that best predicts CAGBD and response to cholecystectomy based on the results of a large prospective study. However, until that study is done, we must use established reference values. Using the standardized methodology, borderline GBEF values below 


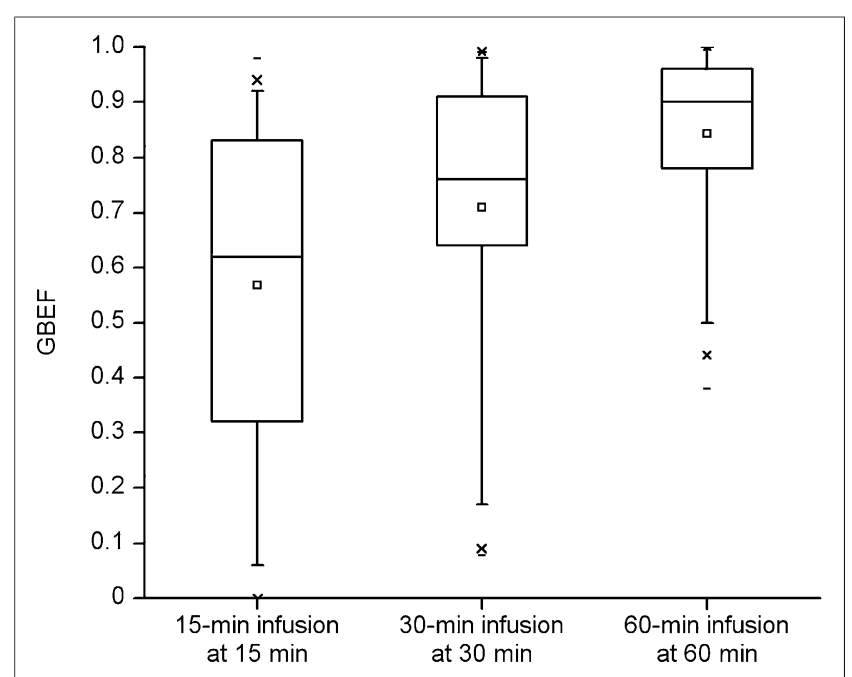

FIGURE 4. Comparison trial of multicenter sincalide infusion method. Box plots show distribution of GBEF values for 3 different infusion groups for different lengths of infusion time. The 60-min infusion had the highest GBEFs and the lowest variability. Boxes represent interquartile range (25th-75th percentiles, median line in center, mean is square), bars represent fifth and 95th percentiles, $\times$ s represent first and 95th percentiles, and dash is minimum and maximum. (Reprinted with permission of (48).)

$38 \%$ should be interpreted with caution. The lower the GBEF, the more confident one can be of the diagnosis.

A GBEF study should be performed on an outpatient basis (57). Acute illness other than gallbladder disease in hospitalized patients can potentially result in a low GBEF. Importantly, many inpatients are taking medications during hospitalization that can inhibit gallbladder contraction (22). These include opiate drugs, atropine, benzodiazepine, ethanol, octreotide, nicotine, nifedipine, pirenzepine, progesterone, and theophylline. In some cases, referring physicians insist. In this situation, a normal GBEF result rules out disease. An abnormal GBEF result should be confirmed on an outpatient basis.

Morphine has a 4- to 6-h half-life and can inhibit sincalide-stimulated gallbladder contraction. Regardless, in approximately $50 \%$ of patients who receive sincalide subsequent to having been administered morphine during cholescintigraphy, the gallbladder contracts normally (58). Again, a normal GBEF result rules out acute cholecystitis or symptomatic chronic gallbladder disease, but a low GBEF is nondiagnostic in this clinical setting (57).

\section{Unavailability of Sincalide}

In 2002 and again this past year, Kinevac was not commercially available because of unspecified production problems (59). Pharmacy-compounded sincalide, produced under state authorization and regulated under the practice of pharmacy, has been used in these circumstances, with some reported success $(60)$. However, concern has been expressed by radiopharmacists that the quality control required for this polypeptide hormone is considerably greater than for many other radiopharmaceuticals that have also been out of production at times, such as dimercaptosuccinic acid and macroaggregated albumin (61). The quality control testing required for sincalide may be beyond the capabilities of some compounding pharmacies and thus may not be performed-for example, testing of the sincalide contractile property using guinea pig gallbladders. The radiopharmacists concluded that using pharmacy-compounded sincalide puts at risk the diagnosis and the physician prescribing the drug.

At least 3 oral cholecystagogues have been studied and reference values established. These include whole milk (300 mL) (62,63), lactose-free EnsurePlus (237 mL [8-oz]; Abbott Laboratories) (64), and Lipomul (a soybean oil emulsion) $(30 \mathrm{~mL})(65)$. After ingestion, images are acquired for $1 \mathrm{~h}$. The lower range of reference values reported for the GBEFs are 51\%, 33\%, and 20\%, respectively. Reference normal values depend on the amount of fat and protein in the administered meal.

\section{BILIARY OBSTRUCTION}

\section{High-Grade}

High-grade biliary obstruction is a surgical emergency. There are 2 types - that caused by tumor and that caused by cholelithiasis. Patients with obstruction caused by tumor, for example, pancreatic cancer, present with painless hyperbilirubinemia. Anatomic imaging will detect dilated biliary ducts and often the tumor causing the obstruction.

Obstruction caused by cholelithiasis presents differently, that is, as acute severe biliary colic. The obstruction causes an increase in intrabiliary duct pressure. Bile flow is reduced, followed by ductal dilatation. However, dilatation of biliary ducts may not be seen on anatomic imaging until 24-72 h after the obstructive event. Thus, ultrasonography findings may be negative when a patient presents in the emergency room with acute pain. It is in these patients that cholescintigraphy can play an important diagnostic role, because the pathophysiologic scintigraphic findings are seen promptly after the obstructive event.

The classic scintigraphic picture of acute high-grade biliary obstruction demonstrates good hepatic uptake and function (rapid blood pool clearance) but no biliary secretion, because of the high intrabiliary back-pressure. Delayed images, even up to $24 \mathrm{~h}$, often show only a persistent hepatogram. With lower degrees of high-grade obstruction, tracer may, over time, enter biliary ducts, but this will be delayed and without biliary-to-bowel transit. If the patient has good hepatic function, high-grade biliary obstruction can often be diagnosed within the first hour of imaging after injection of the ${ }^{99 \mathrm{~m}} \mathrm{Tc}-\mathrm{HIDA}$ radiopharmaceutical. The referring physician should be promptly notified.

With reduced hepatic function, delayed imaging may be required to differentiate biliary obstruction from primary hepatic dysfunction. If biliary obstruction is more chronic, secondary hepatic dysfunction can result and the diagnosis can be uncertain because of the overlap of findings. However, the two can usually be differentiated. Delayed 
transit to the bowel without retention in the biliary ducts is diagnostic of hepatic dysfunction rather than obstruction.

In patients who have had prior biliary obstruction, the biliary ducts often remain dilated, even with appropriate curative therapy. If these patients present again with abdominal pain, the persistently dilated ducts are not diagnostic of obstruction. Physiologic imaging with cholescintigraphy is required to determine whether bile clearance is normal (not obstructed) or delayed (obstructed) $(15,66)$.

\section{Partial}

Partial obstruction presents differently from high-grade obstruction. Patients complain of recurrent biliary colic. Liver function test results are normal. The bile ducts are not dilated. Cholescintigraphic images demonstrate good hepatic uptake, prompt secretion into the biliary ducts, and filling of the gallbladder; however, clearance from the biliary ducts is delayed, best seen in the common hepatic or common bile duct, depending on the site of obstruction. Biliary-to-bowel transit does not exclude partial biliary obstruction. Poor clearance from biliary ducts is diagnostic.

Cholescintigraphy has been found superior to ultrasonography for the diagnosis of partial biliary obstruction (66), with a $98 \%$ sensitivity for $99 \mathrm{~m}$ Tc-HIDA scintigraphy versus $78 \%$ for ultrasonography, and similar specificities of $85 \%-86 \%$. MR cholangiopancreatography is often performed for suspected biliary obstruction. This imaging methodology does well at demonstrating dilated ducts, large stones, and tumors but not so well at detecting small obstructing stones.

Delayed biliary duct clearance and biliary-to-bowel transit with normal hepatic function can have causes other than partial obstruction. Biliary duct retention and delayed biliary-to-bowel transit at $60 \mathrm{~min}$ is seen in up to $20 \%$ of healthy subjects, supposedly due to a hypertonic sphincter of Oddi (67). A functional delay in biliary-to-bowel transit also occurs in up to $50 \%$ of patients who are administered sincalide to empty the gallbladder before cholescintigraphy (68). As the gallbladder relaxes after contraction, a negative pressure within it relative to the biliary ducts results in preferential flow via the cystic duct to the gallbladder rather than through the common duct and into the intestines. Delayed biliary-to-bowel transit is also seen in patients with chronic cholecystitis (13). The reason is uncertain but may be due to an ampullitis caused by recurrent passage of small stones. Pancreatitis has also been associated with delayed transit.

These functional causes of delayed biliary transit can be differentiated from biliary obstruction either by obtaining delayed images or by infusing sincalide. The short half-life of sincalide in the blood $(2.5 \mathrm{~min})$ allows for repeated infusion in patients pretreated with sincalide because they have fasted for more than $24 \mathrm{~h}(69)$. In patients with a functional cause for delayed transit, prompt biliary-to-bowel transit will result from sincalide infusion as the sphincter of Oddi relaxes. If clearance is poor, obstruction must be considered. Sincalide should be infused using the 60-min infusion methodology described above for stimulating gallbladder contraction. Cholelithiasis is not a contraindication to the administration of sincalide.

\section{POSTCHOLECYSTECTOMY PAIN SYNDROME}

The postcholecystectomy pain syndrome refers to the subsequent development of recurrent episodes of abdominal pain in patients who have had cholecystectomy for symptomatic chronic cholecystitis. This syndrome occurs in $10 \%-20 \%$ of postcholecystectomy patients (70). Hepatobiliary causes for the recurrent pain include retained and recurrent stones, biliary stricture, tumors, a cystic duct remnant, and obstruction of the sphincter of Oddi. The explanation for presentation after cholecystectomy is that the biliary system no longer has a pressure-release mechanism, formerly served by the gallbladder. Increased pressure produces the pain.

\section{Sphincter-of-Oddi Dysfunction}

Sphincter-of-Oddi dysfunction is a poorly understood clinical entity that presents weeks, months, or years after cholecystectomy as either recurrent episodic biliary colic pain (stage I), recurrent pain associated with elevated liver enzymes or dilated ducts (stage II), or episodic pain with elevated liver enzymes and dilated biliary ducts (stage III) (71). The cause is a partial biliary obstruction at the level of the sphincter of Oddi, not caused by stones, stricture, or tumor. Two types have been described, stenosis (fixed) and dyskinesia (reversible). Sphincter dysfunction cannot be diagnosed before cholecystectomy (72). Histopathologic findings are often normal, although some patients have inflammation, muscular hypertrophy, fibrosis, or adenomyosis in the papillary zone.

All biliary causes for the postcholecystectomy pain syndrome have a similar scintigraphic pattern on cholescintigraphy, that of a partial biliary obstruction. Qualitative image analysis is often adequate to make the diagnosis (73). Scintigraphy shows prompt hepatic uptake and secretion into the biliary ducts but poor ductal clearance-best visualized in the common duct-seen at $1 \mathrm{~h}$ after injection of the ${ }^{99 \mathrm{~m}}$ Tc-HIDA radiopharmaceutical. At $2 \mathrm{~h}$ no further ductal clearance occurs or retention may be greater than at $1 \mathrm{~h}$.

Quantitative methods have been investigated to diagnose sphincter-of-Oddi dysfunction $(74,75)$. Published reports vary in the selected regions of interest and the quantitative parameters used. One published method originally developed at Johns Hopkins University and still routinely used calls for an initial infusion of sincalide, $0.02 \mu \mathrm{g} / \mathrm{kg}$ over $3 \mathrm{~min}$, with the infusion completed $15 \mathrm{~min}$ before ${ }^{99 \mathrm{~m}} \mathrm{Tc}-$ HIDA injection (75). The infusion was lengthened to $10 \mathrm{~min}$ over a decade ago, probably because of concern about reports that short infusions are disadvantageous for gallbladder contraction. The study is 
acquired for $60 \mathrm{~min}$. The purpose of sincalide infusion is to increase bile flow and thus stress a partially obstructed sphincter, similar to what is done with furosemide renography for suspected renal obstruction. A longer infusion, as recommended for gallbladder contraction, is not used for this indication because its effect would be to relax the sphincter of Oddi, which would be counterproductive to trying to stress the sphincter. Whether the infusion is 3 or $10 \mathrm{~min}$ is probably inconsequential and may even be homeopathic regarding the results because of its short half-life in serum of $2.5 \mathrm{~min}$.

A semiquantitative score is primarily calculated on the basis of image analysis, for example, time of first biliary secretion, percentage of common duct emptying, and time of initial biliary-to-bowel transit. Common duct and liver time-activity curves are generated as ancillary information (75). If the summed score is negative, attention is directed to nonbiliary causes. If positive, endoscopic retrograde cholangiopancreatography (ERCP) is performed to rule out stones, stricture, or tumor. If none of these is found, sphincter-of-Oddi dysfunction is assumed and sphincterotomy often follows.

Enthusiasm for ${ }^{99 \mathrm{~m}}$ Tc cholescintigraphy for sphincter-ofOddi dysfunction has ebbed at some centers because of publications suggesting poor accuracy. One investigation compared 2 different quantitative methods, including the one described above. Elevated basal sphincter pressure detected on sphincter-of-Oddi manometry was the gold standard. The investigation showed that both radionuclide quantitative techniques were inferior to manometry (76). There have been criticisms of the investigation, one of these being that the authors used protocols different from the initially described methods-for example, a 60-min infusion of sincalide rather than 3 or $10 \mathrm{~min}$. Importantly, manometry is seldom used anymore because of the frequent occurrence of serious side effects, particularly pancreatitis.

An independent gold standard superior to manometry would be patient outcome; however, few published data are available. A study subsequent to the ones described above comparing scintigraphy with manometry showed that although scintigraphy was less sensitive, it successfully predicted outcome after sphincterotomy in $93 \%$ of patients, compared with $57 \%$ with manometry (77).

Many centers perform ERCP if the diagnosis is clinically suspected, in order to rule out stones, stricture, and tumor. Once these have been ruled out, a sphincterotomy is performed. However, ERCP by itself is also associated with serious side effects. Other therapies have been investigated, such as drugs, Botox (onabotulinumtoxinA; Allergan Inc.), and stents, but data are limited or inconclusive and further studies are needed. It is my opinion and that of my referring physicians that quantitative cholescintigraphy can be a valuable screening tool for partial biliary obstruction and sphincter-of-Oddi dysfunction. If the results are negative, a nonbiliary cause should be sought. If positive, further biliary investigation is indicated, for example, ERCP.

\section{Biliary Atresia}

Biliary atresia presents as neonatal cholestatic jaundice. It is caused by a progressive inflammatory sclerosis that obliterates extrahepatic and intrahepatic biliary ducts. Early diagnosis is critical and must be made within the first $60 \mathrm{~d}$ of life to prevent irreversible liver failure. Treatment requires a palliative hepatoportoenterostomy (Kasai procedure) and often, ultimately, liver transplantation. The major differential diagnosis includes neonatal hepatitis of various causes.

Patient preparation for cholescintigraphy should include phenobarbital to activate liver excretory enzymes and increase bile flow. With cholescintigraphy, biliary atresia images show a high-grade biliary obstruction, that is, a persistent hepatogram and no biliary-to-bowel transit over $24 \mathrm{~h}$. The negative predictive value of the study is high, approaching $100 \%$. The positive predictive value is said to be lower, and reports have given variable results, on average about $75 \%$ (78). False-positive results occur in some patients with severe parenchymal liver disease, that is, neonatal hepatitis of various causes.

A recently published 20-y experience with 186 infants at a pediatric referral center suggested that if patients receive phenobarbital, $5 \mathrm{mg} / \mathrm{kg} / \mathrm{d}$ for the full $5 \mathrm{~d}$, and have a serum phenobarbital level of more than $15 \mu \mathrm{g} / \mathrm{mL}$ before the ${ }^{99 m}$ Tc cholescintigraphy study, the specificity of the study is very high, with few false-positive results (79).

Cholescintigraphic images should be acquired at multiple times on the day that the ${ }^{99 m}$ Tc-HIDA agent is injected. Acquisition of only infrequent images can miss biliaryto-bowel transit. Imaging up to $24 \mathrm{~h}$ is recommended. Evidence for intestinal activity at any time is diagnostic. Gallbladder filling has the same importance as intestinal activity. With the high back-pressure of the high-grade obstruction seen in biliary atresia, no bile secretion is seen. SPECT/CT can be quite helpful $(27,80)$. A short SPECT acquisition of $10 \mathrm{~min}$ can be diagnostic in uncertain cases (Fig. 5).

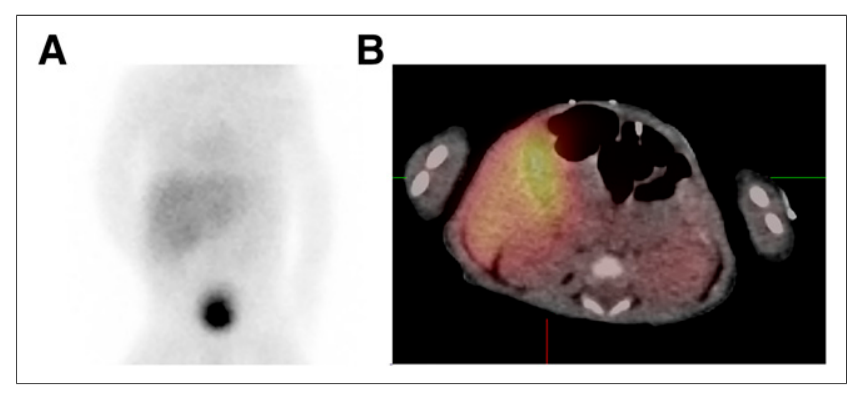

FIGURE 5. Study ordered to confirm or exclude biliary atresia. (A) Six-hour 99mTc-HIDA planar static image shows equivocal gallbladder filling and biliary-to-bowel transit. (B) Ten-minute SPECT/CT acquisition confirms activity in gallbladder, excluding biliary atresia. (Reprinted with permission of (27).) 


\section{CONCLUSION}

For almost 4 decades, cholescintigraphy has been a valuable frequently requested diagnostic radionuclide imaging study. Present-day indications and methodologies have been described, as well as important pharmacologic interventions.

\section{REFERENCES}

1. Loberg MD, Cooper M, Harvey E, Callery P, Faith W. Development of new radiopharmaceuticals based on $\mathrm{N}$-substitution of iminodiacetic acid. $\mathrm{J}$ Nucl Med. 1976;17:633-638.

2. Ziessman HA. Acute cholecystitis, biliary obstruction, and biliary leakage. Semin Nucl Med. 2003;33:279-296.

3. Ziessman HA, Zeman RK, Akin EA, et al. Cholescintigraphy: correlation with other hepatobiliary imaging modalities. In: Sandler MP, Coleman RE, Patton JA, Wackers FJTh, Gottschalk A, eds. Diagnostic Nuclear Medicine. 4th ed., Philadelphia, PA: Lippincott Williams and Williams; 2003.

4. Freitas JE, Coleman RE, Nagle CE, et al. Influence of scan and pathologic criteria on the specificity of cholescintigraphy: concise communication. $\mathrm{J} \mathrm{Nucl}$ Med. 1983;24:876-879.

5. Stadalnik RC, Kraus JF, Matolo M, Krohn KA. The validity of ${ }^{99 \mathrm{~m}}$ Tc-pyridoxlideneglutamate cholescintigraphy as a diagnostic test for cholecystitis. Clin Nucl Med. 1978:3:142-146.

6. Freitas JE, Mirkes SH, Fink-Bennett DM, Bree RL. Suspected acute cholecystitis: comparison of hepatobiliary scintigraphy versus ultrasonography. $\mathrm{Clin} \mathrm{Nucl}$ Med. 1982;7:364-367.

7. Samuels BI, Freitas JE, Bree RL, et al. A comparison of radionuclide hepatobiliary imaging and real-time ultrasound for the detection of acute cholecystitis. Radiology. 1983;147:207-210.

8. Worthen NJ, Uszler JM, Funamura JL. Cholecystitis: prospective evaluation of sonography and ${ }^{99 m}$ Tc-HIDA cholescintigraphy. AJR. 1981;137:973-978.

9. Chatziioannou SN, Moore WH, Ford P, Dheke RD. Hepatobiliary scintigraphy is superior to abdominal ultrasonography in suspected acute cholecystitis. Surgery. 2000;127:609-613.

10. Ralls PW, Colletti PM, Halls JM, Siemsen JK. Prospective evaluation of ${ }^{99 \mathrm{~m}} \mathrm{Tc}-$ IDA cholescintigraphy and gray-scale ultrasound in the diagnosis of acute cholecystitis. Radiology. 1982;144:369-371.

11. Zeman RK, Burrell MI, Cahw CE, Caride V. Diagnostic utility of cholescintigraphy and ultrasonography in acute cholecystitis. Am J Surg. 1981;141:446-451.

12. Tulchinsky M, Ciak BW, Delbeke D, et al. SNM practice guideline for hepatobiliary scintigraphy 4.0. J Nucl Med Technol. 2010;38:210-218.

13. Weissmann HS, Badia J, Sugarman LA, et al. Spectrum of ${ }^{99 \mathrm{~m}} \mathrm{Tc}$-IDA cholescintigraphic patterns in acute cholecystitis. Radiology. 1981;138:167-175.

14. Choy D, Shi EC, McLean RG, et al. Cholescintigraphy in acute cholecystitis: use of intravenous morphine. Radiology. 1984;151:203-207.

15. Weissmann HS, Freeman LM. The biliary tract. In: Freeman LM, ed. Freeman and Johnson's Clinical Radionuclide Imaging. 3rd ed. Philadelphia, PA: W.B. Saunders Company; 1984.

16. Al-Sheikh W, Hourani M, Barkin JS, et al. A sign of symptomatic chronic cholecystitis on biliary scintigraphy. AJR. 1983;140:283-285.

17. Freeman LM, Sugarman LA, Weissmann HS. Role of cholecystokinetic agents in 99mTc-IDA cholescintigraphy. Semin Nucl Med. 1981;11:186-193.

18. Chamarthy M, Freeman LM. Hepatobiliary scan findings in chronic cholecystitis. Clin Nucl Med. 2010;35:244-251.

19. Fink-Bennett D, Balon H, Robbins T, Tsai D. Morphine-augmented cholescintigraphy: its efficacy in detecting acute cholecystitis. J Nucl Med. 1991;32:12311233.

20. Kim CK, Tse KK, Juweid M, et al. Cholescintigraphy in the diagnosis of acute cholecystitis: morphine augmentation is superior to delayed imaging. $\mathrm{J} \mathrm{Nucl}$ Med. 1993;34:1866-1870.

21. Ziessman HA. Interventions used with cholescintigraphy for the diagnosis of hepatobiliary disease. Semin Nucl Med. 2009;39:174-185.

22. Kistler AM, Ziessman HA, Gooch D, Bitterman P. Morphine-augmented cholescintigraphy in acute cholecystitis: a satisfactory alternative to delayed imaging. Clin Nucl Med. 1991;16:404-406.

23. Holbrooke RF, Jacobson FL, Pezzuti RT, et al. Biliary patency imaging after endoscopic retrograde sphincterotomy with gallbladder in situ: clinical impact of nonvisualization. Arch Surg. 1991;126:738-741.

24. Kalff V, Froelich JW, Lloyd R, Thrall JH. Predictive value of an abnormal hepatobiliary scan in patients with severe intercurrent illness. Radiology. 1983;146: 191-194.
25. Fig LM, Wahl RL, Stewart RE, Shapiro B. Morphine-augmented hepatobiliary scintigraphy in the severely ill: caution is in order. Radiology. 1990;175:467473.

26. Coleman RE, Freitas JE, Fink-Bennett DM, Bree RL. The dilated cystic duct sign: a potential cause of false negative cholescintigraphy. Clin Nucl Med. 1984:9:134-136.

27. Ziessman HA, O'Malley JP, Thrall JH, Fahey FH. Hepatobiliary system. In: Ziessman HA, O'Malley JP, Thrall JH, Fahey FH., eds. Nuclear Medicine: The Requisites. 4th ed. Philadelphia, PA: Elsevier; 2014.

28. Kaplun L, Weissmann HS, Rosenblatt R, et al. Early diagnosis of common bile duct obstruction using cholescintigraphy. JAMA. 1985;254:2431-2434.

29. Meekin GK, Ziessman HA, Klappenbach RS. Prognostic value and pathophysiologic significance of the rim sign in cholescintigraphy. J Nucl Med. 1987;28: 1679-1682.

30. Smith R, Rosen JM, Gallo LN, et al. Pericholecystic hepatic activity in cholescintigraphy. Radiology. 1985;156:797-800.

31. Brachman MB, Tanasescu DE, Ramanna L, et al. Acute gangrenous cholecystitis: radionuclide diagnosis. Radiology. 1984;151:209-211.

32. Fink-Bennett D, Clark K, Tsai D, et al. In-111 leukocyte imaging in acute cholecystitis. J Nucl Med. 1991;32:803-804.

33. Lantto E, Järvi K, Laitinen R, et al. Scintigraphy with ${ }^{99 \mathrm{~m}} \mathrm{Tc}-\mathrm{HMPAO}$ labeled leukocytes in acute cholecystitis. Acta Radiol. 1991;32:359-362.

34. Gracie WA, Ransohoff DF. The natural history of silent gallstones: the innocent gallstone is not a myth. N Engl J Med. 1982;307:798-800.

35. Raymond F, Lepanto L, Rosenthall L, et al. Tc-99m-IDA gallbladder kinetics and response to CCK in chronic cholecystitis. Eur J Nucl Med. 1988;14:378381.

36. Chen PF, Nimeri A, Pham QH, Yuh JN, Gusz JR, Chung RS. The clinical diagnosis of chronic acalculous cholecystitis. Surgery. 2001;130:578-581.

37. Dunn FH, Christensen ED, Reynolds J, et al. Cholecystokinin cholecystography: controlled evaluation in the diagnosis and management of patients with possible acalculous gallbladder disease. JAMA. 1974;228:997-1003.

38. Goldberg HI. Cholecystokinin cholecystography. Semin Roentgenol. 1976;11: 175-179.

39. Krishnamurthy GT, Bobba VR, Kingston E. Radionuclide ejection fraction: a technique for quantitative analysis of motor function of the human gallbladder. Gastroenterology. 1981;80:482-490.

40. Topper TE, Ryerson TW, Nora PF. Quantitative gallbladder imaging following cholecystokinin. J Nucl Med. 1980;21:694-696.

41. Fink-Bennett D, DeRidder P, Kolozsi WJ, et al. Cholecystokinin cholescintigraphy: detection of abnormal gallbladder motor function in patients with chronic acalculous gallbladder disease. J Nucl Med. 1991;32:1695-1699.

42. Ziessman HA. Functional hepatobiliary disease: chronic acalculous gallbladder and chronic acalculous biliary disease. Semin Nucl Med. 2006;36:119-132.

43. Yap L, Wycherley AG, Morpett AD, et al. Acalculous biliary pain: cholecystectomy alleviates symptoms in patients with abnormal cholescintigraphy. Gastroenterology. 1991;101:786-793.

44. Drane WE, Johnson DA. Sincalide-augmented quantitative hepatobiliary scintigraphy. J Nucl Med. 1990;31:1462-1468.

45. Sarva RP, Shreiner DP, Van Thiel D, Yingvorapant N. Gallbladder function: methods for measuring filling and emptying. J Nucl Med. 1985;26:140-144.

46. Ziessman HA, Fahey FH, Hixson DJ. Calculation of a gallbladder ejection fraction: advantage of continuous sincalide infusion over the three-minute infusion method. J Nucl Med. 1992;33:537-541.

47. Ziessman HA, Muenz LR, Agarwal AK, ZaZa AA. Normal values for sincalide cholescintigraphy: comparison of two methods. Radiology. 2001;221:404-410.

48. Ziessman HA, Tulchinsky M, Lavely C, et al. Sincalide-stimulated cholescintigraphy: a multicenter investigation to determine optimal infusion methodology and gallbladder ejection fraction normal values. J Nucl Med. 2010;51:277-281.

49. Hedner P, Lunderquist A. Use of the c-terminal octapeptide of cholecystokinin for gallbladder evacuation in cholecystography. AJR. 1972;116:320-326.

50. Torsoli A, Ramorino ML, Colagrande C, Demaio G. Experiments with cholecystokinin. Acta Radiol. 1961;55:193-206.

51. Hopman WP, Jansen JB, Rosenbusch G, et al. Gallbladder contraction inducted by cholecystokinin: bolus injection or infusion? $\mathrm{Br}$ Med J (Clin Res Ed). 1986;292:375-376.

52. Smythe A, Majeed AW, Fitzhenry M, et al. A requiem for cholecystokinin provocation test? Gut. 1998;43:571-574.

53. DiBaise JK, Richmond BK, Ziessman HA, et al. Cholecystokinin-cholescintigraphy in adults: consensus recommendations of an interdisciplinary panel. Clin Nucl Med. 2012;37:63-70.

54. DiBaise JK, Richmond BK, Ziessman HA, et al. Cholecystokinin-cholescintigraphy in adults: consensus recommendations of an interdisciplinary panel. Clin Gastroenterol Hepatol. 2011;9:376-384. 
55. Ziessman HA. Sincalide cholescintigraphy-32 years later: evidence-based data on its clinical utility and infusion methodology. Semin Nucl Med. 2012;42:79-83.

56. Richmond BK, DiBaise J, Ziessman H. Utilization of cholecystokinin cholescintigraphy in clinical practice. J Am Coll Surg. 2013;217:317-323.

57. Ziessman HA. Cholecystokinin cholescintigraphy: victim of its own success? J Nucl Med. 1999;40:2038-2042.

58. Achong DM, Oates E. Normal gallbladder ejection fraction after morphine augmentation. Clin Nucl Med. 1999;24:837-841.

59. Ziessman HA, Petry NA. Sincalide is temporarily unavailable-again. $J \mathrm{Nucl}$ Med. 2013;54(8):17N

60. Krishnamurthy S, Cerulli-Switzer J, Chapman N, Krishnamurthy GT. Comparison of gallbladder function obtained with regular CCK-8 and pharmacy-compounded CCK-8. J Nucl Med. 2003;44:499-504.

61. Norenberg JP, Ponto JA, Petry NA, Wittstrom KM. Prescriber beware: it is ill advised to administer compounded sincalide. J Nucl Med. 2013;54(11):23N-24N.

62. Xynos E, Pechlivanides G, Zoras OJ, et al. Reproducibility of gallbladder emptying studies. J Nucl Med. 1994;35:835-839.

63. Mackie CR, Baxter JN, Grime JS, et al. Gallbladder emptying in normal subjects: a data base for clinical cholescintigraphy. Gut. 1987;28:137-141.

64. Ziessman HA, Jones DA, Muenz LR, Agarval KA. Cholecystokinin cholescintigraphy: methodology and normal values using a lactose-free meal food supplement. J Nucl Med. 2003;44:1263-1266.

65. Bartel TB, Juweid ME, Ponto JA, Graham MM. Corn oil emulsion: a simple cholecystagogue for diagnosis of chronic acalculous cholecystitis. J Nucl Med. 2005;46:67-74.

66. Zeman RK, Lee C, Jaffe MH, et al. Hepatobiliary scintigraphy and sonography in early biliary obstruction. Radiology. 1984;153:793-798.

67. Williams W, Krishnamurthy GT, Brar HSS, Bobba VR. Scintigraphic variations of normal biliary physiology. J Nucl Med. 1984;25:160-165.

68. Kim CK, Palestro CJ, Solomn RW, et al. Delayed biliary-to-bowel transit in cholescintigraphy after cholecystokinin treatment. Radiology. 1990;176:553556.
69. Sostre S, Canto MI, Kaloo AN. Gallbladder response to a second dose of cholecystokinin during the same imaging study. Eur J Nucl Med. 1992;19:964-965.

70. Black NA, Thompson E, Sanderson CF. Symptoms and health status before and six weeks after open cholecystectomy: a European cohort study. ECHSS Group. European Collaborative Health Services Study Group. Gut. 1994;35:1301-1305.

71. Hogan WJ, Geenen JE. Biliary dyskinesia. Endoscopy. 1988;20:179-183.

72. Kalloo AN, Sostre S, Meyerrose GE, Pasricha PJ, Szabo Z. Gallbladder ejection fraction: nondiagnostic for sphincter of Oddi dysfunction in patients with intact gallbladders. Clin Nucl Med. 1994;19:713-719.

73. Zeman RK, Burrell MI, Dobbins J, et al. Postcholecystectomy syndrome: evaluation using biliary scintigraphy and endoscopic retrograde cholangiopancreatography. Radiology. 1985;156:787-792.

74. Corazziari E, Cicala M, Habib FI, et al. Hepatoduodenal bile transit in cholecystectomized subjects: relationship with sphincter of Oddi function and diagnostic value. Dig Dis Sci. 1994;39:1985-1993.

75. Sostre S, Kalloo AN, Spiegler EJ, et al. A noninvasive test of sphincter of Oddi dysfunction in postcholecystectomy patients: the scintigraphic score. $\mathrm{J} \mathrm{Nucl}$ Med. 1992;33:1216-1222.

76. Cicala M, Scopinaro F, Corazziari E, et al. Quantitative cholescintigraphy in the assessment of choledochoduodenal bile flow. Gastroenterology. 1991;100:11061113.

77. Cicala M, Habib FI, Vavassori P, et al. Outcome of endoscopic sphincterotomy in post-cholecystectomy patients with sphincter of Oddi dysfunction as predicted by manometry and quantitative choledochoscintigraphy. Gut. 2002;50:665-668.

78. Kwatra N, Shalaby-Rana E, Narayanan S, Mohan P, Ghelani S, Majd M. Phenobarbitalenhanced hepatobiliary scintigraphy in the diagnosis of biliary atresia: two decades of experience at a tertiary center. Pediatr Radiol. 2013;43:1365-1375.

79. Kianifar HR, Tehranian S, Shojaei P, et al. Accuracy of hepatobiliary scintigraphy for differentiation of neonatal hepatitis from biliary atresia: systematic review and meta-analysis of the literature. Pediatr Radiol. 2013;43:905-919.

80. Sevilla A, Howman-Giles R, Saleh H, et al. Hepatobiliary scintigraphy with SPECT in infancy. Clin Nucl Med. 2007;32:16-23. 